\title{
Holocene land-cover change in Eastern Asia for climate modeling
}

\section{Shijazhuang, China, 9-11 October 2012}

\author{
Marie-José Gaillard ${ }^{1}$ and QInghal Xu ${ }^{2}$ \\ 'Department of Biology and Environmental Science, Linnaeus University, Kalmar, Sweden; marie-jose.gaillard-lemdahl@Inu.se \\ ${ }^{2}$ Key Laboratory of Environmental Change and Ecological Construction, Hebei Normal University, Shijiazhuang, China
}

$T^{1}$ his workshop was held at Hebei Normal University in China, and contributed to the PAGES Focus 4 theme Land Use and Cover (LUC). A major goal of LUC is to achieve Holocene land-cover reconstructions that can be used for climate modeling and testing hypotheses on past and future effects of anthropogenic land cover on climate. Collaborations initiated between Linnaeus University (Sweden; M.-J Gaillard), University of Hull (Britain, Jane Bunting), Hebei Normal University (China; Q. Xu and Y. Li), the French Institute (Pondicherry, India; A Krishnamurthy) and Lucknow University (India; P. Singh Ranhotra) are in line with the goals of Focus 4-LUC and follow the strategy of the European LUC-relevant LANDCLIM project (Gaillard et al. 2010). The aim of these collaborations is to develop quantitative reconstructions of past vegetation cover in India and China using pollen-vegetation modeling and archaeological/historical data together with other land-cover modelling approaches.

The objective of this workshop in China was to initiate the necessary collaborations and activities to make past land-cover reconstructions possible in Eastern Asia. The three major outcomes of the workshop are (i) the building of a large network of experts from Eastern Asia, Europe and USA now working together to understand past changes in land use and land cover in Eastern Asia, (ii) that all existing East Asian pollen databases will be integrated into the NEOTOMA Paleoecology Database by 2014 (coordinated by Eric Grimm, Illinois State University, USA), and (iii) that a review paper will be prepared with the working title "Past land-use and anthropogenic land-cover change in Eastern Asia - evaluation of current achievements, potentials and limitations, and future avenues". It is planned to submit this article this fall. It will include 1) a review of Holocene human-induced vegetation and land-use changes in Eastern Asia based on results presented at the workshop; 2) a discussion of the existing anthropogenic land-cover change scenarios (HYDE, Klein Goldewijk et al. 2010; KK 10, Kaplan et al. 2009) in the light of the reviewed proxy-based knowledge; and 3) a discussion on the implications of these results for future climate modeling and the study of past land cover-climate interactions.

These significant outcomes are the result of three intense days of presentations and discussion sessions. During the lectures, results were presented for historical, paleoecological and pollenbased reconstructions; pollen-vegetation relationships; past human-impact studies; and model scenarios of anthropogenic land-cover changes in the past. Some of the conference was also dedicated to reviewing the state of existing pollen databases and more generally, database building.

Plenary and group break-out discussions focused on more technical aspects such as improving pollen databases, especially for the East Asian region; planning the review paper; and scientific topics such as the use of pollen-based and historical land-cover reconstructions for the evaluation of model scenarios of past anthropogenic land-cover change (Fig. 1), and the integration of model scenarios with paleoecological or historical reconstructions.

\section{References}

Gaillard MJ et al. (2010) Climate of the Past 6: 483-678

Kaplan J, Krumhardt K, Zimmermann N (2009) Quaternary Science Reviews 28: 3016-3034

Klein Goldewijk K, Beusen A, Janssen P (2010) The Holocene 20: 565-573 Olofsson J, Hickler T (2008) Vegetation History and Archaeobotany 17: 605-615

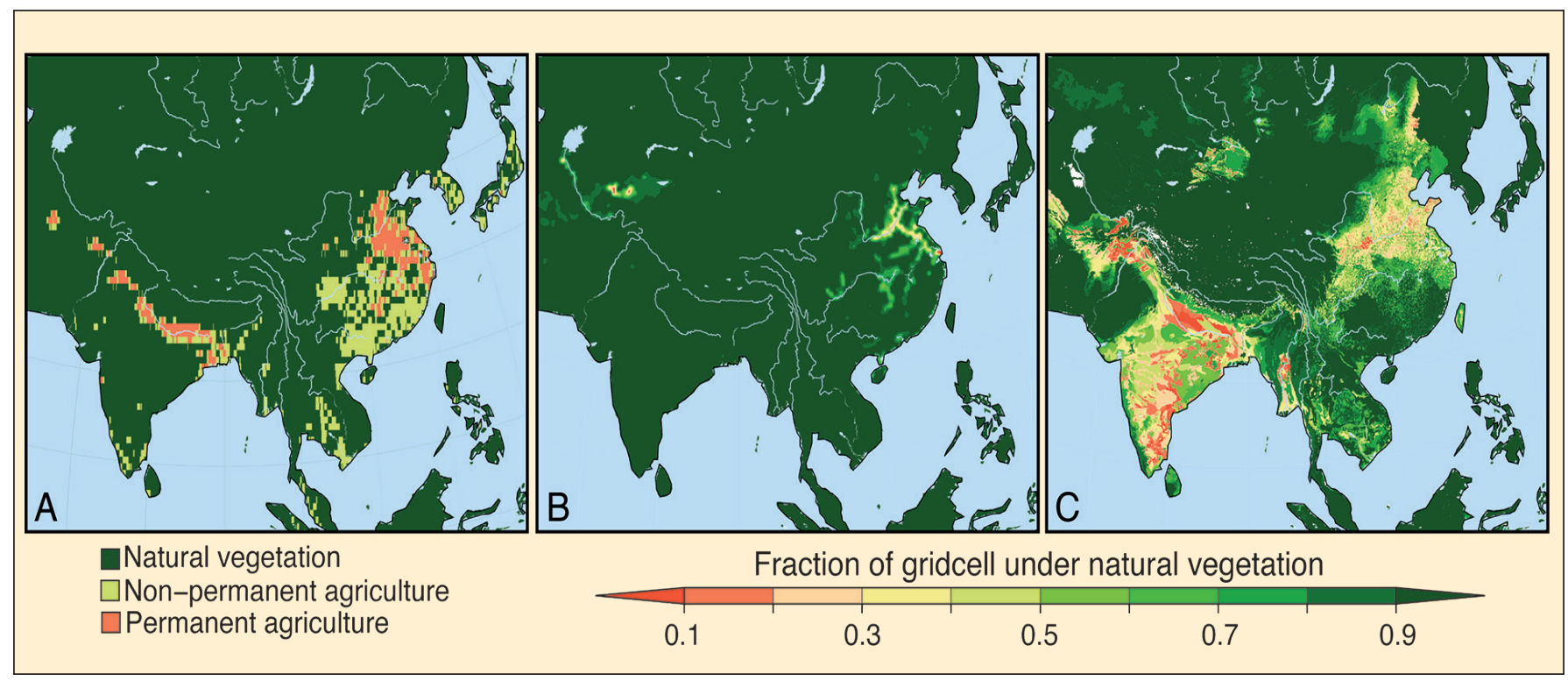

Figure 1: Anthropogenic deforestation in Eastern Asia at AD 1 simulated by three different approaches: A) Olofsson and Hickler (2008); (B) HYDE (History Database of the Global Environment) version 3.1 (Klein Goldewijk et al. 2010); and (C) Kaplan et al. (2009). Note the large differences in land-cover between the different models used. 